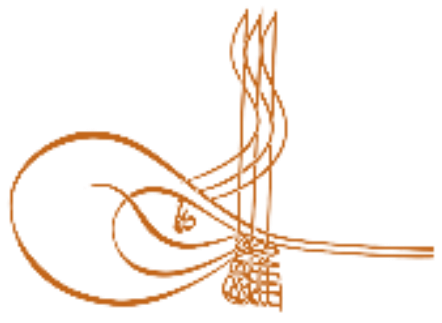

www.turkishstudies.net/social
Turkish Studies - Social Sciences

eISSN: $2667-5617$

Research Article / Araştırma Makalesi

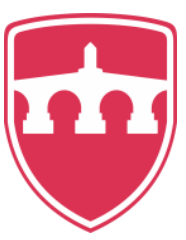

INTERNATIONAL

BALKAN

UNIVERSITY

Sponsored by IBU

\title{
Phrygler Dinsel Mekânlarını Nasıl Koruyordu? Midas Vadisi Kaleleri
}

How did the Phrygians Protect Their Religion Spaces? The Fortresses of Midas Valley

\author{
Yusuf Polat ${ }^{*}$
}

\begin{abstract}
With its deep valleys and steep tufa rockwork, the Highlands of Phrygia Region is protected in itself. Of these valleys, the Yazıllkaya/Midas Valley located approximately 70 kilometers south of Eskisehir is home to five fortress settlements dated to the Phrygian Period. Perched atop inaccessible rocky hills, the fortresses built-in position to control entrance and exit to the valleys were surrounded by forest and agricultural land. All of these fortresses were located along the route heading to Midas Fortress and were positioned close to one another. Thusly, transport along the route could be easily controlled from these forts. In addition to the bedrockcarved residences, silos, cisterns, and living spaces connected with stairs or ladders of the fortresses found in this valley (Akpara, Gökgöz, Pişmiş, Kocabaş, Yazllıkaya/Midas), some of the rockwork surrounding the fortresses are also home to rock-cut tombs of varying periods. Along with architectural remains belonging to these living spaces, there are also cultic monuments built for religious practices in or around some of these fortresses. These consist of fairly small and monument-sized facades, altars, and niches built in honor of the mother goddess Matar, Matar Areyastin, Matar Kubileya who the Phrygians embraced to the point of believing her to be the single, unrivaled deity after they migrated from Thrace to Anatolia in the $12^{\text {th }}$ century BCE. These monuments were built using the easily-carved volcanic tufa found in nature and placed at the entrances to settlements, in high places, near sources of water and alongside fields, and at times at the entrance to fortresses to be used in ritual practices meant to protect and bring fertility and plenty. In this paper, we'll discuss the fortresses in this valley and what can be described as a religious sanctuary of the Phrygians living in these fortresses: the Yazılıkaya/Midas Fortress.
\end{abstract}

Structured Abstract: The Phrygians, who are believed to have immigrated to Anatolia from Macedonia and Thrace in a few waves beginning at the end of the $2^{\text {nd }}$ millennium BCE, became a Central Anatolian politic power in the $9^{\text {th }}$ century BCE. The area in the Upper Sakarya Valley between Eskisehir, Afyonkarahisar, and Kütahya where the Phrygians held the most political and cultural influence is the Mountainous Phrygia Region known as "Little Phrygia" during the Classical Period. The area known as Mountainous Phrygia is home to rough terrain with a defensive advantage surrounded by large, fertile plains suitable for agriculture. The region's southern and southeastern areas are home to elevated ridges separated by deep valleys. These valleys are surrounded by plateaus and low mountains comprised of easily-carved, volcanic tufa.

\footnotetext{
${ }^{*}$ Dr. Öğr. Üyesi, Anadolu Üniversitesi, Edebiyat Fakültesi, Arkeoloji Bölümü Asst. Prof. Dr., Anadolu University, Faculty of Letters, Department of Archaeology ORCID 0000-0002-1455-8318 ypolat@anadolu.edu.tr

Cite as/ Atıf: Polat, Y. (2020). Phrygler dinsel mekânlarını nasıl koruyordu? Midas vadisi kaleleri, Turkish Studies Social, 15(2), 317-334. https://dx.doi.org/10.29228/TurkishStudies.40039

Received/Geliş: 06 December/Aralık 2019

Accepted/Kabul: 25 February/Şubat 2020

Copyright $($ INTAC LTD, Turkey
} 
This area was continuously inhabited throughout the ages thanks to its abundance of wetlands and defensively strategic topography. In addition to its political and cultural importance, this is a region, with 24 currently known Phrygian fortress settlements dating to between the $8^{\text {th }}$ century BCE and the first half of the $6^{\text {th }}$ century BCE, in which interpreting the Phrygian's defense system and strategies possible. With its fortress settlements nearly lined up one after another, this place is the Yazıllkaya/Midas Valley located south of Eskisehir within the borders of Mountainous Phrygia. In addition to the information gathered since the $19^{\text {th }}$ century by researchers and travelers to the region, research carried out in the region has shown that this valley in Mountainous Phrygia is home to extensive numbers of Phrygian settlements and stone monuments built in honor of the mother goddess Matar.

The Midas Fortress is located $30 \mathrm{~km}$ south of Eskisehir's Seyitgazi District, $13.5 \mathrm{~km}$ northwest of the Han District, and $75 \mathrm{~km}$ from Eskisehir itself. Positioned on top of the rockwork southwest of Yazılıkaya Village, the Yazılıkaya/Midas Fortress has been referred to as 'Midas City' by some researchers. The Phrygians built numerous cultic monuments consisting of facades, altars, and niches where they would worship the Mother Goddess Matar into the rockwork, hillsides, and anywhere with suitable rock composition. Cisterns, both small and monumental, water collection pools, and vaulted gateways are also present in this settlement. The area is surrounded by rock-cut tombs and residences dating to the Phrygian, Hellenistic, Roman, and Byzantine Periods. Adorned with cultic structures, this settlement appears to be a kind of regional sanctuary.

The only fortress settlement in the valley to have been excavated in definite intervals is the Yazılikaya /Midas Fortress. In 1936, Director of the Istanbul French Archeology Institute, Art Historian and Architect A. Gabriel began the first excavations on behalf of the French Archeology Institute. In addition to a small number of ceramic sherds dated to the Early Bronze Age, artifacts dating to the $2^{\text {nd }}$ century BCE and the Phrygian, Hellenistic, and Roman Periods were discovered during the short-lived excavations of at the fortress. Whether considering the short-lived excavations carried out at the fortress or the artifacts recovered during newly performed surveys, the structural foundations belonging to the settlement and the stone monuments seen on site indicate that the Midas Fortress was a significant settlement during the Middle Phrygian Period.

Another reason for the high number of fortresses in the Yazılıkaya-Midas Valley is the presence of large scale monuments (façade, altar, and niches) carved into the tufa located in this valley. The YazılıkayaMidas Valley was an important settlement area for the Phrygian Civilization, the City at Yazılıkaya-Midas a religious metropolis. For this reason, the Phrygians constructed fortresses using the natural rockwork on the rocky hilltops above transit points to strengthen their defensive formation and protect their holy sanctuaries. The fortresses in the Yazılıkaya-Midas Valley are separated by an average distance of $1.5 \mathrm{~km}$. The Kocabaş Fortress is located $2000 \mathrm{~m}$ east of the Yaz1lıkaya-Midas Fortress. It's rocky, tree-covered, makeshift construction gives the impression of a less than a defensively strong fortress. However, when viewed from the east, the fortress's steepening cliff-side reaches a height of $64 \mathrm{~m}$ and appears quite formidable. This Fortress served as a preliminary patrol to the Pişmiş Fortress. It also constituted the mountainous region's northern border. Pişmiş Fortress is found 1500m northeast of the Yazılıkaya Fortress. Described as a border patrol station located on the 'King's Road', Pişmiş Fortress was an important fortress settlement thanks to its location. Akpara Fortress is located 1350m northeast, Gökgöz Fortress 470 m south, Kocabaş Fortress 950m southeast, and the Areyastis Monument 1250m west of Pişmiş Fortress.

These fortresses are scattered throughout the valley and not connected by any straight line. They were positioned far from one another due to the vast length and width of the valley, as well as the width of its passes, created by the steeply descending extensions of the Turkmen Mountain's slopes reaching the valley's southern side. The fortresses are extensive on the eastern side of the valley; that is to say, to the west of the YazllikayaMidas Valley. Fortresses in Kümbet Valley must have been related to the Yazllıkaya-Midas Fortress because the southwestern entrance to the Yazllıkaya-Midas Valley is the eastern entrance to the Kümbet Valley.

Located on the edge of plateaus or at high, inaccessible points where they can control entrance and exit to the valleys, these fortresses are noteworthy for their proximity to the surrounding agricultural and forested land. Thanks to their strategic locations, they are all quick and easy to defend. Due to their positions overlooking the roads, nearby routes could be easily controlled from these fortresses.

Most of these fortresses sit atop high, independent hills. Additionally, they are positioned near agricultural areas and sources of water, facing in directions from which they can control their surroundings. The monuments found in Yazllıkaya-Midas Valley and Kümbet Valley to its southeast, in particular, indicate

Turkish Studies - Social, 15(2) 
that these valleys were the Phrygians most important holy areas. For this reason, defensive fortresses were built making use of the valley's topographic make up.

Keywords: Archaeology, Phrygians, Highlands of Phrygia, Phrygian Monuments (façade, altar, and niches), Yazılıkaya/Midas Fortress.

Öz: Dağlık Phrygia Bölgesi’nde yer alan derin vadiler, yüksek ve dik tüf kayalıkları ile korunaklı bir set oluşturmaktadır. Bu vadilerden Yazılıkaya/Midas Vadisi'nde Phryg Dönemi'ne tarihlenen 5 adet kale yerleşmesi bulunmaktadır. Ulaşılması güç, yüksek tepelerin üzerindeki kayalık alanlarda, vadilerin girişçıkışlarını kontrol edebilecek noktalarda yer alan kalelerin etrafı tarım ve ormanlık arazilerle çevrilidir. Bu kalelerin tümü Midas Kale'ye ulaşan yol güzergâhı üzerinde olup, birbirlerine yakın mesafede konumlanmışlardır. Böylece yol güzergâhı kalelerden rahatlıkla kontrol edilebilmektedir. Vadide bulunan kalelerde (Akpara, Gökgöz, Pişmiş, Kocabaş, Yazılıkaya/Midas Kale) ana kayanın işlenmesiyle oluşturulan mekânlar, silolar, sarnıçlar, merdivenlerle birbirlerine bağlanan yaşam alanlarına ait mekânlar, bazı kalelerin çevresindeki, kayalıklarda, farklı dönemlere tarihlenen kaya mezarları da yer alır. Bu yaşam alanlarına dair mimari kalıntıların yanı sıra bazı kalelerde ve kalelerin çevresinde dinsel uygulamalar için yapılmış, kült anıtları bulunmaktadır. Bunlar, Phryglerin M.Ö. 1200'lerde Thrakia'dan Anadolu'ya geldiklerinde, Anadolu'daki ana tanrıça inancını benimseyerek adeta tek tanrı olarak inandıkları Matar, Matar Areyastin, Matar Kubileya için yapmış oldukları küçük ve anıtsal boyutlardaki fasad, altar ve nişlerden oluşan kült anıtlarıdır. Bu anıtlar, doğada hazır bulunan ve kolay işlenebilen tüf kayalıklar kullanılarak, yerleşim alanlarının girişlerinde, yüksek yerlerde, su kaynakları yakınında ve tarla kenarlarında, bazen de kalelerin girişlerinde, berekete, bolluğa ve korunmaya yönelik ritüel eylemler için yapılmıştır. Bu çalışma ile vadide bulunan kaleler ve bu kalelerin Phryglerin dinsel alanı olarak görülen Yazılıkaya/Midas Kale ayrıntılı olarak irdelenecektir.

Anahtar Kelimeler: Arkeoloji, Phrygler, Dağlık Phrygia Bölgesi, Phryg Kült Anıtları (Fasad, Altar, Niş), Yazılıkaya/Midas Kale.

\section{Giriş}

M.Ö. 2. Binyıl'ın sonlarından itibaren Makedonia ve Thrakia'dan Anadolu'ya birkaç akınla göç ettiği düşünülen Phrygler, (Herodotos. VII, 73; Strabon. XII, 3.20; Plinius. V, 41.145; Stephanus Byzantinos. 186, 12), M.Ö. 9. yy'dan itibaren, Orta Anadolu'da siyasi bir güç olarak yerini almıştır. Phryglerin siyasi ve kültürel açıdan en etkili oldukları alan, Yukarı Sakarya Vadisi'nde Eskişehir, Afyonkarahisar ve Kütahya illeri arasında kalan, klasik dönemde "Küçük Frigya" olarak adlandırılan Dağlık Phrygia Bölgesi'dir. Dağlık Phrygia olarak adlandırılan bölge; savunma açısından avantajlı, engebeli arazi yapısına ve arazilerin etrafinda tarıma elverişli geniş, verimli ovalara sahiptir. Bölgenin güneyinde ve güneydoğusunda yükseltiler ve bu yükseltiler arasında kalan derin vadiler bulunur. $\mathrm{Bu}$ vadiler kolay şekilde işlenebilir volkanik tüf kayalarından oluşan platolar ve fazla yüksek olmayan dağlar ile çevrelenmiştir. Yazılıkaya/Midas Vadisi ve çevresi aynı zamanda Dağlık Phrygia Bölgesi’nin büyük bölümünün kaya birimi "Üçüncü Zaman" a ait volkanik tüftür (Chaput, 1941: 38-39; Haspels, 1971: 21). Tüfün volkanik malzemenin sıkışması sonucu oluştuğu bilinmektedir. Tüfün, zamanında bölgede var olan bir volkan bacasından çıkan malzemenin göl ortamında sıkışması sonucunda oluştuğu düşünülmektedir (Chaput, 1941: 68; Ayday ve Göktan, 1990: 102; Ayday ve Göktan, 1993: 156).

Topografyanın savunmaya elverişli, sulak arazilerinin bolluğu nedeni ile bu alan farklı dönemlerde sürekli yerleşim görmüştür. Bu bölge, siyasi ve kültürel öneminin yanı sıra M.Ö. 8.yy ile M.Ö. 6. yüzyılın ilk yarısı içine tarihlendirilen şu ana kadar bilinen 24 adet Phryg kale yerleşmesi ile Phryglerin savunma sistemleri ve stratejilerinin yorumlanabileceği bir bölgedir (Polat, 2009: 109, harita: 4). Kale yerleşmelerinin adeta birbiri ardına sıralandığı yer, Eskişehir'in güneyinde bulunan ve Dağlık Phrygia Bölgesi sınırları içerisinde kalan Yazılıkaya/Midas Vadisi'dir. Bölgeye 19. yy'dan itibaren gelen seyyah ve araştırmacıların verdikleri bilgilerin yanı sıra, bölgede gerçekleştirilen 
araştırmalar, Dağlık Phrygia'daki bu vadide, özellikle Phryg yerleşmelerinin ve ana tanrıça Matar için yapılmış kaya anıtlarının yoğun olduğunu göstermiştir.

Yazılıkaya/Midas Kenti kutsal alanının seçiminde topoğrafyanın önemi en büyük etkenlerden biridir. Zira vadiyi çevreleyen yükseltilere kale üzerinden kuzey yöne doğru bakıldığında, vadiyi kuzey ve batı yönde sıralanmış Kocabaş, Pişmiş, Gökgöz ve Akpara Kalelerinin arasında boyut bakımından yerleşime müsait tek yükseltinin Yazılıkaya/Midas Kale olduğu anlaşılmaktadır. Aynı zamanda bu yükseltiler üzerinde bulunan kayalık alanlarda dinsel içerikli anıt yapmaya müsait tek alan yine Yazılıkaya/Midas Kale'dir (Harita 1).

Harita 1: Yazilıkaya/Midas Vadisi ve Kaleler (COpenTopoMap, uygulama: Y.Polat)

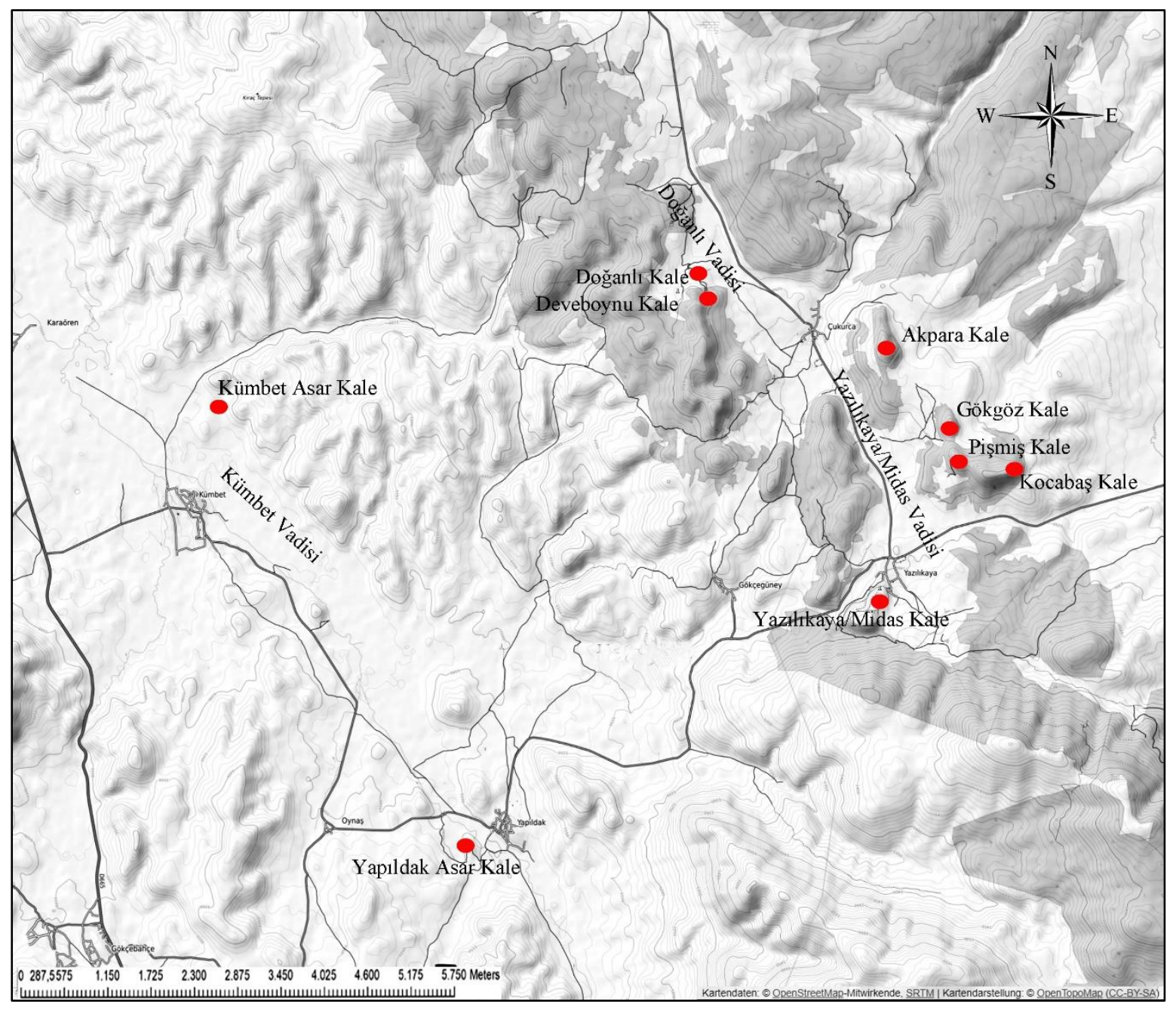

Turkish Studies - Social, 15(2) 


\section{Yazılıkaya/Midas Vadisi}

Günümüz Eskişehir İli’nin yaklaşık olarak $70 \mathrm{~km}$ güneyinde, Han ve Seyitgazi İlçeleri sinırlarında kalan Yazılıkaya/Midas vadisi kuzeydoğu-güneybatı doğrultusunda $1800 \mathrm{~m}$. uzunluğundadır. Kuzeydoğu yönden vadiye giriş $1250 \mathrm{~m}$. uzunluğundadır. Güneybatısı ise Yazılıkaya/Midas Kale'nin de bulunduğu alana doğru 180 m.'ye kadar daralmaktadır. Vadi güney ve batıda alçalır. Bu alçalma ile aradaki kaya yüzeyi açı̆̆a çıkar, güneybatı ve batı kenarlarda platoyu kuşatır ve bu teras, yüksek yerler Phryg kalelerine dâhil edilir (Resim: 1).

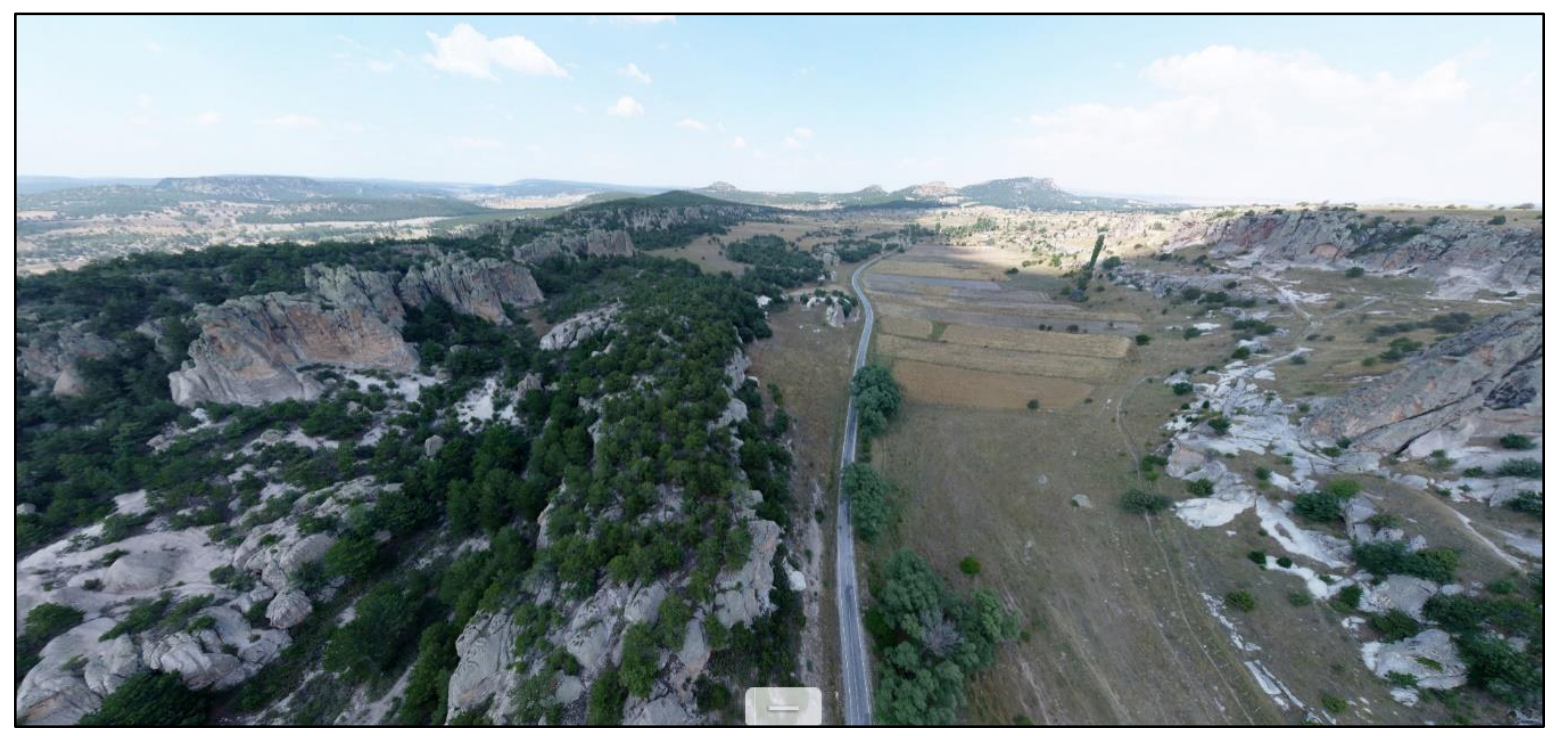

Resim 1: Yazılıkaya/Midas Vadisi Genel Görünümü

Vadinin ortasından bugün Eskişehir'den (Dorylaion) Seyitgazi’ye (Nakoleia) buradan da Kümbet'e (Meros) doğru giden karayolu geçmektedir. Bu yol ağının antik dönemde aynı yol güzergâhını takip ettiği bilinmekle birlikte karayolunun her iki tarafında yükseltisi fazla olmayan kayalıklar, s1k bitki örtüsü ile çevrelenmiştir.

Pekçok kültüre ev sahipliği yapan vadi, özellikle bu uygarlıklar içinde Phryg Uygarlığı'na ait yerleşimlerin ve kaya anıtlarının en anıtsal ve tekil örneklerini barındırması nedeniyle, aslında yalnızca Phryg Dönemi ile sınırlandırılamayacak olmasına karşın, literatürde "Phryg Vadileri" olarak yerini almıştır (Tamsü Polat, 2018: 263). 
Yazılıkaya/Midas Vadisi'nin güneydoğu noktasında, Yazılıkaya/Midas Kale'nin $3300 \mathrm{~m}$. kuzeyinde ise Akpara Kale bulunur. Yazılıkaya/Midas Kale üzerinden kuzey yöne doğru bakıldığında, birbiri ardına sıralanmış, vadiyi kuzey ve batı yönden sınırlandıran Kocabaş, Pişmiş, Gökgöz ve Akpara Kaleler görülmektedir (Resim: 2). Yazılıkaya/Midas Vadisi'nin kuzeybatısında Doğanlı Vadisi ve bu vadi içerisinde, Doğanlı Kale ve Deve Boynu Kalesi bulunmakta, olasılıkla hem Doğanlı Vadisi'ne hem de Midas Vadisi'ne giriş-çıkısı kontrol eden birer ön karakol niteliğinde olmalıdırlar. Vadinin güneybatısında ise Yapıldak ve Kümbet Vadisi'ne açılan 180 m'ye kadar daralan bir geçit bulunmakta ve bu alanın konumu nedeniyle Yazılıkaya-Midas Kale ile bağlantılı olmalidir.

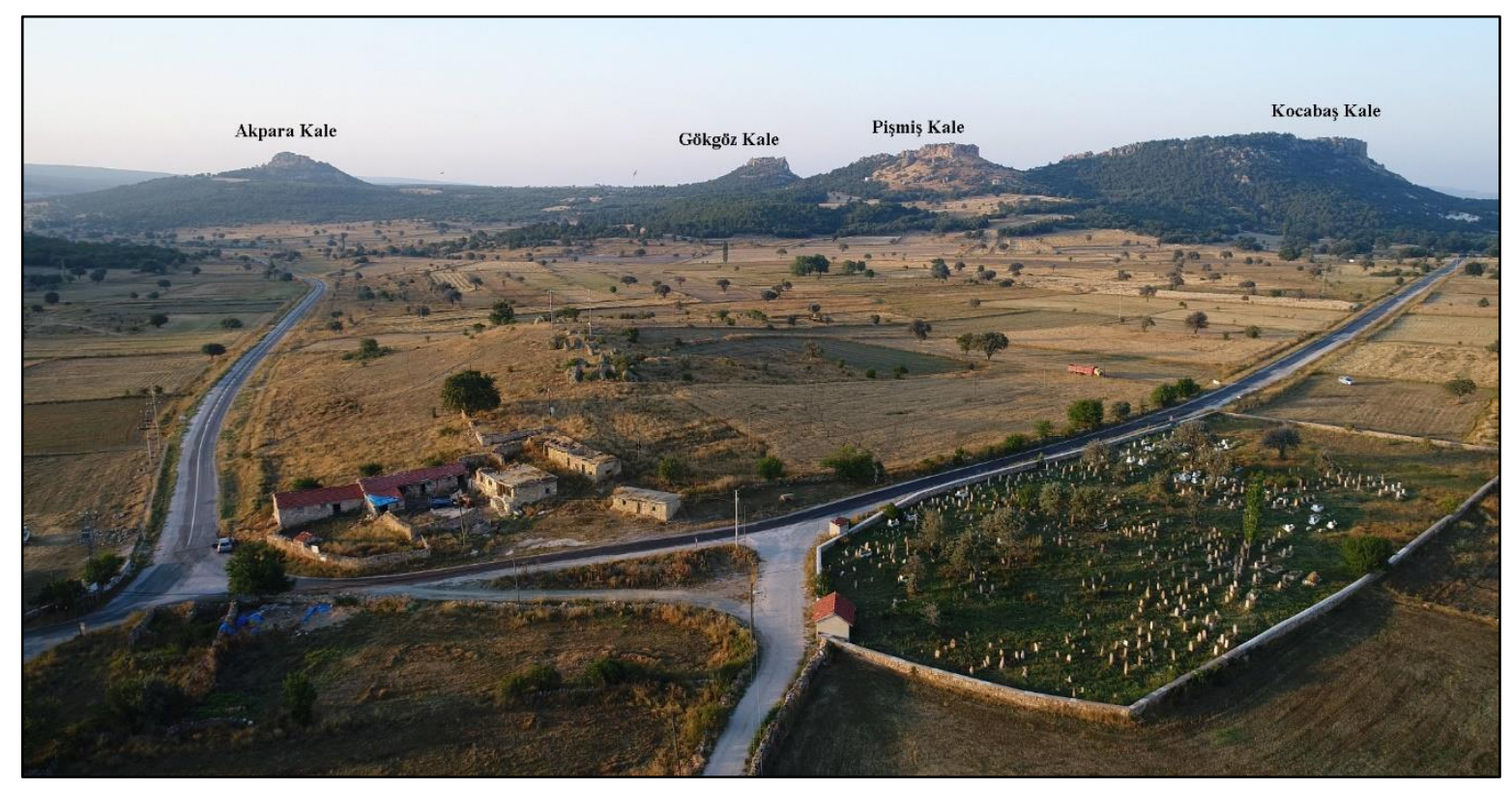

Resim 2: Yazılıkaya/Midas Kale'den Vadideki Diğer Kalelerin Görünümü

\section{Yazılıkaya/Midas Kale}

Eskişehir İli, Seyitgazi İlçesi’nin 30 km. güneyinde, Han İlçesi’nin 13,5 km. kuzeybatısında, Eskişehir'e $75 \mathrm{~km}$. uzaklıktadır. Yazılıkaya Köyü'nün güneybatısındaki kayalık alan üzerinde kurulan kale tipi yerleşim alanı, bazı araştırmacılar tarafından "Midas Şehri" olarak adlandırılmaktadır (Haspels, 1971: 36; Talbert, 2000: 964). Üst kısmı düz kayalık platodan oluşan kale yerleşiminin kuzeydoğu-güneybatı yönünde uzunluğu 800 m'dir. Kuzeydoğusu 235 m., güneybatıs $350 \mathrm{~m}$. genişliğindeki platonun özellikle güney uca doğru yükseltisi artar. Kuzey ve doğu kenarlarda platonun yüksekliği eşittir. Yakın çevresi çam ve meşe ormanlarılla kaplı, doğusunda Toptepe, güneyinde Deveeriği Tepesi, batısında kayalık yükseltiler ile çevrelenmiş antik dönem yerleşim standartlarına uygun bir alandır. Bu kale yerleşimi, Yazılıkaya Köyü'nün hemen batısındadır. Köy, 1885 yılında Kafkasya'dan göç eden Çerkez göçmenleri tarafından iskân edilmiş olup, adını da köyün hemen güneybatısında bulunan anıtsal boyutlardaki, üzerinde Paleo-Phrygce yazıtın bulunduğu Yazılıkaya'dan yani Midas Anıtı'ndan almıştır (Haspels, 1981: 2). Kalenin güneyinden ve batısından günümüzde sadece bahar aylarında aktif hale gelen bir dere geçmektedir. Bunun yanı sıra su kaynakları açısından zengin bir alandadır. Günümüzde aktif halde beş adet çeşme bulunmaktadır ki bu su kaynaklarından, kalenin batısında bulunan çeşmenin antik dönemde de aktif olma olasılığı yüksektir. 
Kayalık alanın üstünde, eteklerinde ve çevresinde kaya yapısının uygun olduğu noktalarda Phrygler, tapınımda bulundukları, Ana Tanrıça Matar adına çok sayıda fasad, altar ve nişlerden oluşan kült anıtlarını yapmışlardır (Haspels, 1971; Tüfekçi Sivas, 1999; Tamsü Polat 2010: 204-221). Yerleşimin üzerinde anıtsal ve küçük boyutta sarnıçlar, su biriktirme havuzları, tonozlu geçitler de görülmektedir. Alan Phryg, Hellenistik, Roma ve Bizans Dönemlerine tarihlenen kaya mezarları ve kaya mekânları ile çevrilidir. Bu yerleşme, kült yapılarıyla donatılmış, adeta bölgenin kutsal alanı görünümündedir (Resim 3).

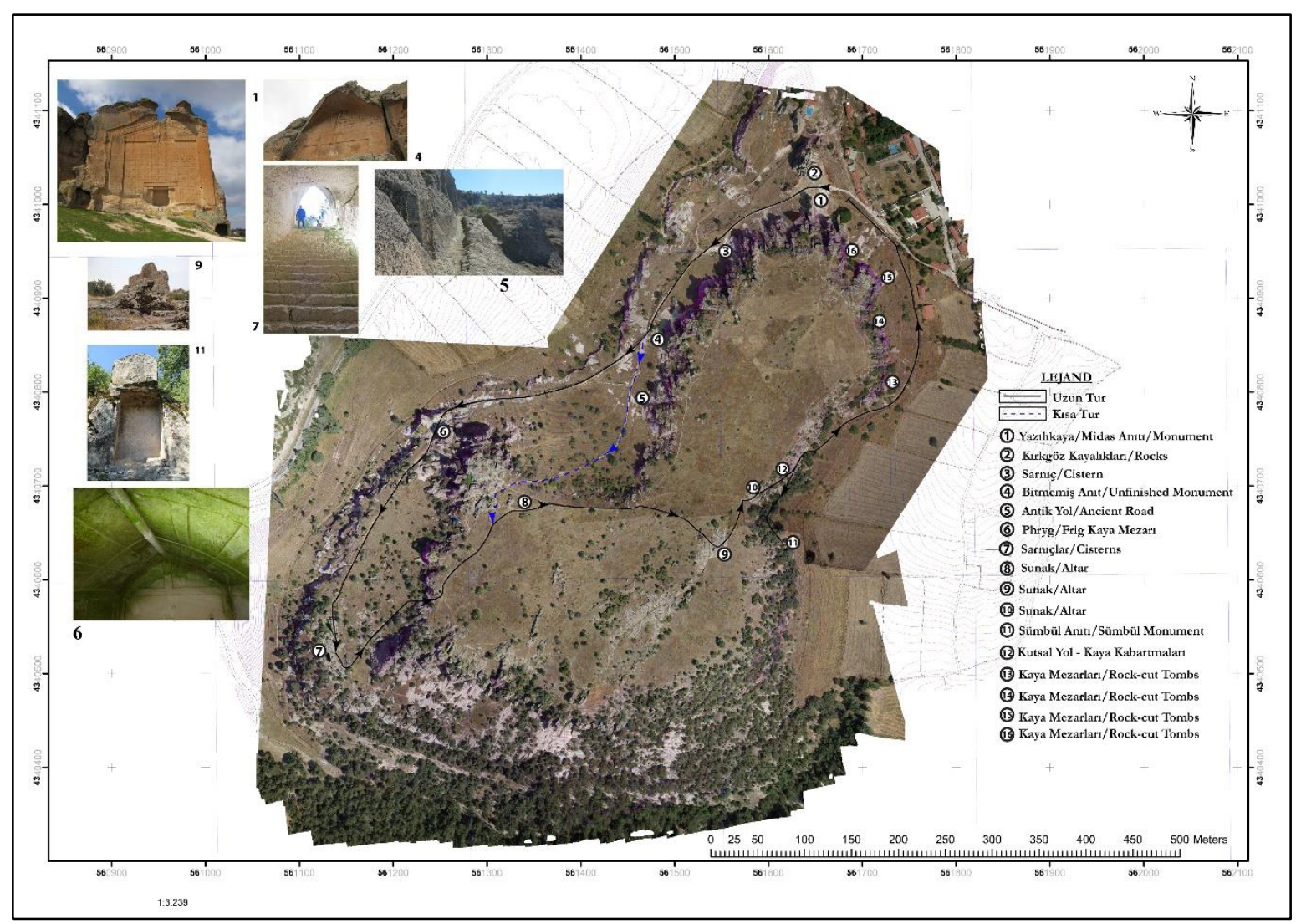

\section{Resim 3: Yazılıkaya/Midas Kale}

Midas Kale, vadi içindeki konumu, yerleşimde çeşitlilik gösteren kaya anıtlarının varlığı gibi nedenlerden ötürü araştırmacıların ilgisini her zaman çekmiştir. İlk olarak 1800'lü yıllarda gezgin ve yazar W. M. Leake Yazılıkaya/Midas Vadisi'nde araştırmalarda bulunmuş, Midas Kale'deki anıtları incelemiş, bugün Midas Anıtı olarak adlandırılan kaya anıtının üzerinde bulunan paleo-phrygçe yazıttaki Midai kelimesinden yola çıkarak anıtın Midas'a ait olduğunu belirtmiştir (Leake, 1824: 3132). 1834 yılında, mimar-arkeolog C. Texier'in Midas Anıtı ve Bitmemiş Anıt ile vadideki kaya mezarlarının gravür çizimlerini yapması ile birlikte (Texier, 1839: 154-155) vadi ve vadideki anıtlar pek çok araştırmacı ve gezginin dikkatini çekmiş, 19. ve 20. yy'da bölgeye bu ziyaretler devam etmiştir (de Laborde, 1938: 74-75; Steuart, 1842: 8-9; Barth, 1860: 91-92; Ramsay, 1888: 374; Radet, 1895: 425; Körte ve Körte, 1904: 219-226; von Diest, 1898: 22-32; von Reber, 1897: 562; Mordtmann, 1925: 542; Chaput, 1941: 38-39).

Vadide belirli aralıklar ile kazısı yapılan tek kale yerleşimi Yazılıkaya/Midas Kale'dir. 1936 yılında Fransız Arkeoloji Enstitüsü adına, İstanbul Fransız Arkeoloji Enstitüsü müdürü, Sanat Tarihçisi ve Mimar A. Gabriel tarafından ilk kazılar başlatılmıştır. Ardından Atina'daki Fransız 
Arkeoloji Enstitüsü'nden Arkeolog C. H. E. Haspels kazılara katılması için davet edilmiş, 1939 yılına kadar bu kazılarda Haspels arazi başkanlığ görevini üstlenmiştir. Bu çalışmalar sırasında anıtların çevresi, sarnıçlar ve ovaya doğru inen merdivenlerin temizliği yapılıp, Midas Kale'nin kuzeydoğu kesimindeki yerleşim birimleri ile Phryg seramikleri gün 1şı̆̆ına çıkartılmıştır (Haspels, 1948: 535-537; Gabriel, 1948: 225-227; Gabriel, 1952: 27). II. Dünya Savaşı nedeniyle kazılara ara verilmiş, 1948 yılında İstanbul Fransız Arkeoloji Enstitüsü adına Midas Kale'de yeniden kazılar başlamıştır. 1951 yılına kadar süren kazıların arazi başkanlığını da H. Çambel yürütmüştür (Gabriel, 1965: 1). Çambel tarafından yönetilen çalışmalar sırasında Midas Kale'nin doğusunda tespit edilen İlk Tunç Çağı mezarlığında da kazılar yapılmıştır (Haspels, 1971: 285; Çambel, 1948: 228-229). Bu kazı çalışmalarından sonra alanda herhangi bir kazı yapılmamış ancak 1970'li ve 1990'lı yıllarda Ankara ve Eskişehir Müzesi tarafından kısa süreli temizlik, onarım çalışmaları gerçekleştirilmiştir (Haspels, 1981: 1-3; Özçatal, 1992: 209-232; Özçatal, 1993: 419-439). 1992-1996 yılları arasında ise T. Tüfekçi Sivas, doktora tezi kapsamında Dağlık Phrygia Bölgesi'nde araştırmalar yaparken, Midas Kale'deki kaya anıtlarını da ayrıntılı olarak incelemiştir (Tüfekçi Sivas, 1999: 52-65, 127 135, 158-167, 175-176). 2001-2007 y1lları arasında da bu bölgedeki araştırmalarını sürdürmüştür (Tüfekçi Sivas, 2003: 285-298; Tüfekçi Sivas ve Sivas, 2003: 2-32). 1999-2006 yıllarında R.E. Kortanoğlu, doktora tezi kapsamında dağlık bölgedeki Hellenistik ve Roma Dönemi'ne tarihlenen kaya mezarlarını araştırmış, bu çalışması kapsamında Midas Vadisi'ndeki kaya mezarlarını da ele almıştır (Kortanoğlu 2008). 2017 yılından itibaren başta Midas Kale olmak üzere, Yazılıkaya/Midas Vadisi'nde, R. Tamsü Polat'ın başkanlığında, arkeolojik araştırmaların yanısıra belgeleme çalışmalarının ağırlıklı olduğu yüzey araştırmaları çalışmaları gerçekleştirilmektedir (Tamsü Polat, 2018; Tamsü Polat ve Polat, 2018; Tamsü Polat vd., 2019;).

Kalede kısa süreli yapılan kazılarda M.Ö. II. Binyıl, Phryg, Hellenistik Roma Dönemi’ne tarihlendirilen buluntuların (Haspels, 1971: 36, fig. 494, A) yanı sıra İlk Tunç Çağı'na tarihlenen az miktardaki seramik parçası da ortaya çıkarılmıştır. Fakat bu seramik parçalarının bulunduğu yer ve tabaka hakkında ayrıntılı bir bilgi verilmemiştir (Çambel, 1952: 229). Aynı zamanda kayalık Midas platosunun doğusunda bulunan yol boyunca kaya yüzeyine işlenmiş günümüzde kaya yüzeyi aşınması nedeniyle dikkatli bakılınca görülebilen kabartmalar bulunmaktadır. Bu kabartmaların Hitit Dönemi'ne tarihlendiği araştırmacılar tarafindan belirtilir (Berndt, 2002: 72; Haspels, 1971: 83; Ramsay, 1882: 8).

Gerek kalede yapılan kısa süreli kazı çalışmaları gerekse de yapılan yeni yüzey araştırmaları sonucu ortaya çıkarılan buluntular, yerleşime dair temel kalıntıları ve alanda görülen kaya anıtları Midas Kale'nin Orta Phryg Dönemi'nde önemli bir yerleşme olduğunu gösterir (MÖ 800-540), (Henrickson, 1994: 110, 111, 112; Voigt, 2012: 69; Kealhofer, vd., 2019: 498). Kalenin kuzey ucunda yüksek bir tüf kaya kütlesinin doğu yüzünde bulunan Midas Anıtı, 17 m yüksekliği, 16,50 m genişliği ile diğer Phryg anıtları içerinde en anıtsal olanıdır. Anıt diğer Phryg fasadlarında olduğu gibi bir tepe akroteri, üçgen alınlı̆̆ı, çatı orta dikmesi, bezemeli cephesi ile dikkat çekmektedir. Ayrıca bu anıtın çatı üst pervazı ile anıtın cephe yanlarında Paleo-phrygce yazıt bulunur. Midas Anıtı için M.Ö. 8. yüzyıl gibi erken bir tarih önerilmesine rağmen (Haspels, 1971: 108-109), dağlık bölgelerindeki diğer anıtlar için önerilen tarihler ise M.Ö. 8. yüzyıl ile M.Ö. 6. yüzyıl sonu arasındadır (Haspels, 1971: 146 (8. yüzyıl); Naumann 1983: 293-94 (6. yüzyılın başları); Prayon 1987: 206-207 (6. yüzyılın sonları). L.E. Roller ise yazıtların özelliklerinden yola çıkarak Midas Anıtı'nın M.Ö. 7. yüzyıl başı ve 6. yüzyıl ortaları arasında bir zaman aralığını vermektedir (Roller, 1999: 112). Anıtın tarihlendirmesine ilişkin farklı yorumlar bulunmasına karşın, bu kalede bulunan Bitmemiş Anıt ile Yazılıkaya Köyü'ne 1,1 km uzaklıkta, Pişmiş Kale'nin karşısında yer alan Areyastis Anıtı'nın cephesindeki mimari detaylar, Midas Anıtı'nın daha önce yapılmış bir anıt olduğunu düşündürmektedir (Resim 4). Bahsi geçen Bitmemiş Anıt ile Areyastis Anıtı'nın cephe detayları, özellikle Lydia Uygarlı̆̆ında mimari yapıların cephelerini süsleyen pişmiş toprak kaplama levhaları andırmaktadır. Bu nedenle bu benzerlik anıtların Lydia hâkimiyeti Dönemi'ne 
tarihlenebileceğini düşündürmektedir. Özellikle her iki anıttaki bezeme unsurları, alınlıktaki pencere detayları da iki anıtın çağdaş olduğu izlemini vermektedir (Roller, 2102: 218).

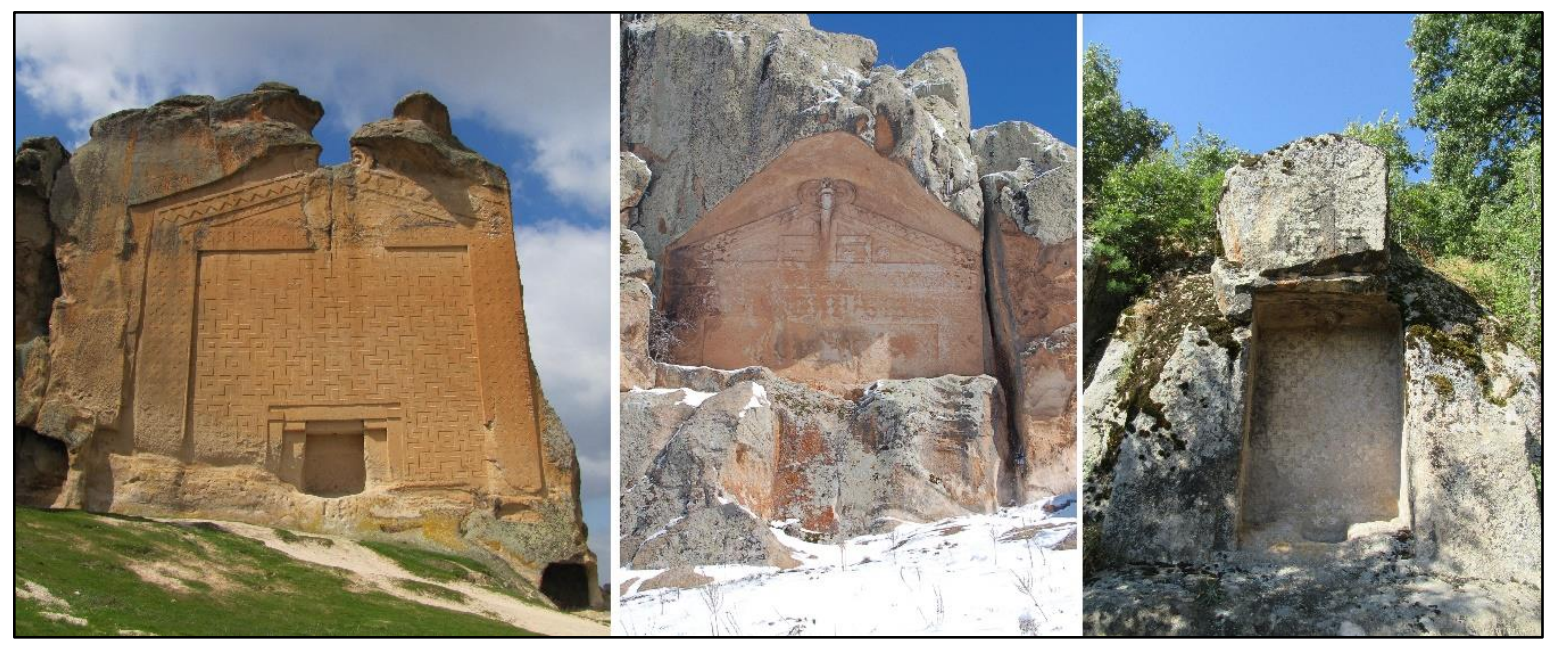

Resim 4: Yazılıkaya/Midas Anıtı, Bitmemiş Anıt, Sümbüllü Anıtı

Midas Kale'de yapılan yeni yüzey araştırmalarında kale ve eteklerinde bulunan seramikler arasında Phryg seramikleri, M.Ö. 9. yy'dan- M.Ö. 6. yy'a kadar tarihlenmekle birlikte, seramik grupları içerisinde özellikle M.Ö. 8. yy'a tarihlenen seramiklerin daha yoğun olduğu saptanmıştır. Bu yerleşim, Orta Phryg Dönemi'nde, etrafı surlarla çevrili büyük bir yerleşmedir. Yapılan kazı ve araştırmalar sonucunda sur bedenine ait in-situ duvar tespit edilemediği yönünde bilgiler olmasına karşın (Taciser Sivas, 2012: 129) son yıllarda yapılan arkeolojik yüzey araştırmaları sonucunda kalenin güneydoğusunda in-situ duvarlar tespit edilmiştir. Bu duvar kalıntıları basamak oluşturularak yapılmış ana kayalar içerisine bu duvarların nasıl yerleştirildiğini göstermesi açısından önemli bir tespittir (Resim: 5-6). Dik ve sarp kayalardan oluşan doğal bir savunma sistemi Yazılıkaya/Midas Kale yerleşmesini çevrelemektedir. Ana kayaların, savunmayı zafiyete uğrattığı boşluklar ise basamaklı bir şekilde tıraşlanarak taş bloklar ile örülmüştür. Günümüzde taş blokların yerleştirildiği basamaklar, ana kayaya oyulmuş blokların oturtulduğu yuvalar ve taş blokların küçük bir bölümü kalenin güneydoğusunda bulunan ana kayada görülmektedir. 


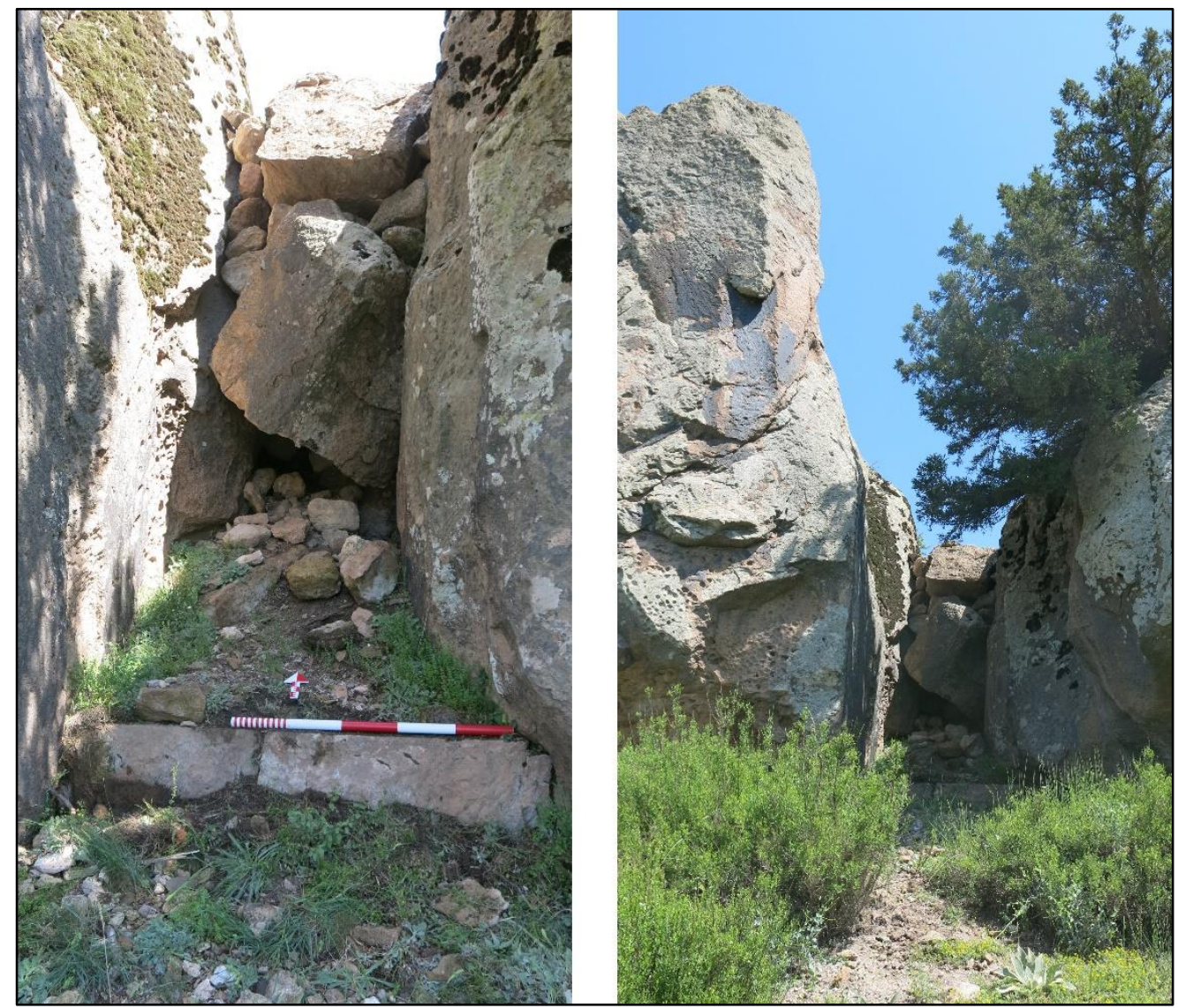

Resim 5-6: Yazılıkaya/Midas Kale in situ Duvar Kalıntısıve Genel Görünüm

Tarihi İlk Tunç Çağı'na kadar dayanan yerleşme Phryg Dönemi’nde de kült anıtları ile donatılarak dinsel bir alan haline gatirilmiş olmalıdır.

Orta Phryg Dönemi dışında, 1930'lu yıllarda yapılan arkeolojik kazılarda M.Ö. 540-330 yıllarına tarihlendirilen arkeolojik buluntular yoğun olarak tespit edilmiş, M.Ö. 4. yüzyılın sonlarına doğru kale yerleşmesi aniden terkedilmiştir. Bu dönemlerde Anadolu'da Pers hâkimiyeti altındadır (Haspels, 1971: 141). Roma ve Bizans Dönemi’ne ait kaya mezarları ve kaya mekânları da Yazılıkaya (Midas) Kale'nin bu dönemde de yoğun bir şekilde kullanıldığını göstermektedir (Haspels, 1971: 112; Kortanoğlu, 2008: 97-98).

\section{Kocabaş Kale}

Eskişehir ili, Han ilçesine bağlı Yazılıkaya Köyü’nün 2000 m. doğusunda yer almaktadır. Kocabaş veya Topbaş Kale bir dağ yamacı boyunca uzanmaktadır. Taşlı, ağaçlıklı ve eğreti yapısı, savunma açısından çok iyi bir kale olmadığı izlenimini uyandırmaktadır. Ancak, kalenin doğu tarafında dikleşen ve 64 m'lik bir yüksekliğe ulaşan yamaç, kaleye bu açıdan bakıldığında heybetli bir görünüm vermektedir. Bu Kale, Pişmiş Kale'nin bir ön karakolu niteliğindedir. Aynı zamanda dağlık bölgenin kuzey sınırını teşkil eder. Doğu bölümünde platonun orta alanında kayaya oyulmuş bazı geniş mekân temelleri bulunmaktadır. Zemin üzerine açılmış çok sayıda küçük yuvarlak çukurlar, sarnıç veya silo olarak kullanılmıştır. Dörtlü grup kalelerin güneydoğusundaki son kaledir. Kocabaş Kale'nin doğu tarafında birkaç adet büyük odadan başka bir şey bulunmamaktadır. Kalenin güneydoğu tarafinda ise yerleşim alanı olduğuna dair izlere rastlanılmaktadır. Yazılıkaya-Midas 
Vadisi'nin güneydoğu yöndeki son uç noktasında yer alan bu kale, Phrygia topraklarına giden tarihi Kral Yolu'na bakmaktadır. Kral Yolu'nu gözetlemek amacı ile kullanılan bir uç karakol noktası gibidir. Bu amaçla kullanıldığı da kesindir (Haspels, 1971: 45-46, fig. 58-59, $494 \mathrm{E}$ ).

A. Gabriel tarafından tespit edilerek harita üzerine işaretlenmiş, fakat kale ile ilgili bilgi verilmemiştir. 1946-1958 yılları arasında C.H.E. Haspels, Dağlık Phrygia Bölgesi'nde yapmış olduğu yüzey araştırmalarında kaleyi detaylı olarak incelenmiştir (Haspels, 1971: 40-45, fig. 58-59, 494 E ). 1980'li yılların sonunda İtalyan araştırmacı Geza de Francovich tarafından araştırılan Kocabaş Kale'nin ismi Kokabaş Kale olarak adlandırılmıştır (Haspels, 1971: 47). Yoğun bitki örtüsü ile kaplı olması nedeniyle kalenin yüzeyinde bugün arkeolojik kalıntıları takip etmek zordur (Resim 7).

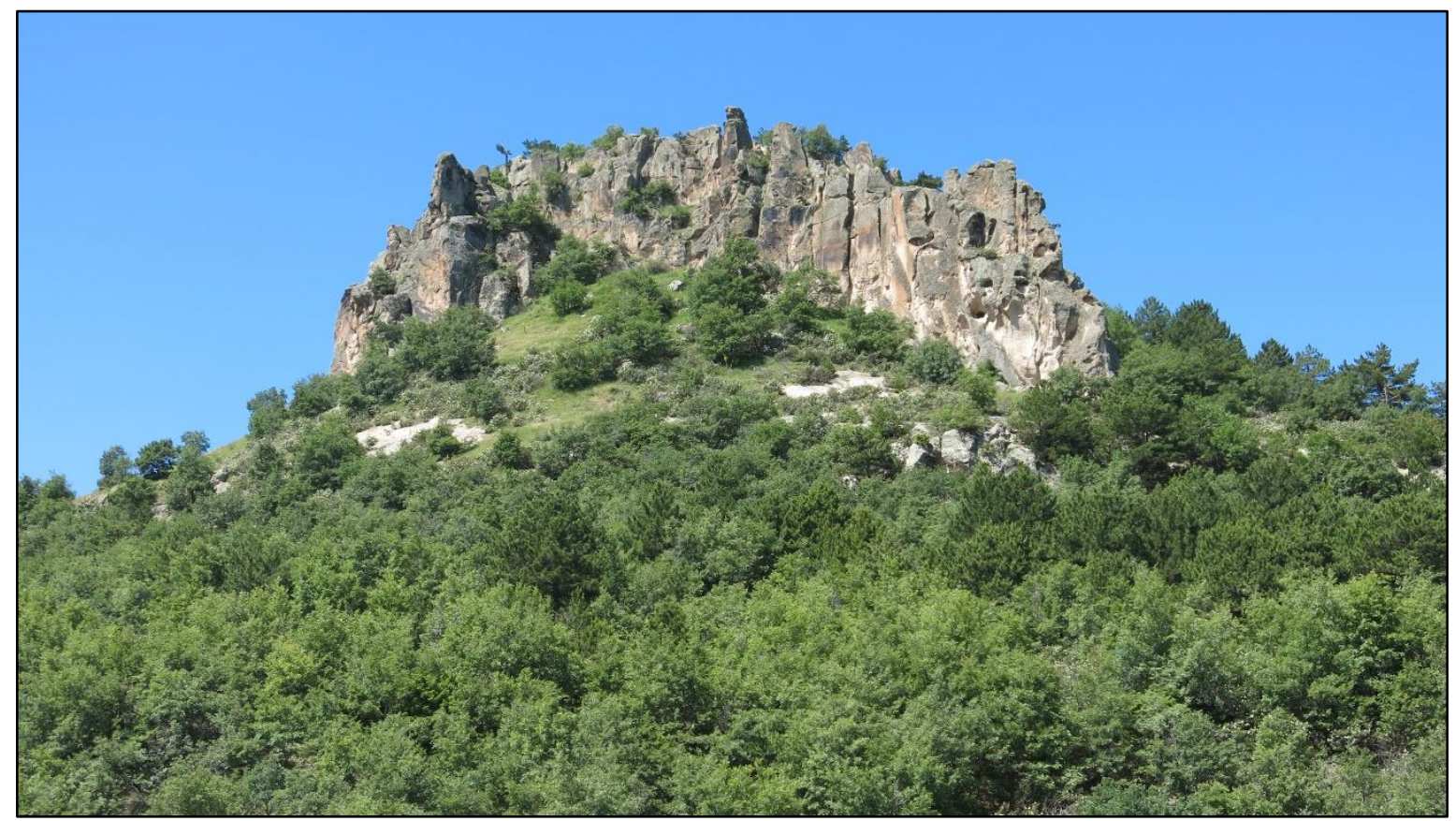

Resim 7: Kocabaş Kale

\section{Pişmiş Kale}

Yazılıkaya Vadisi'ne hâkim bir noktada savunma amaçlı kaleler arasında Pişmiş Kale, Yazılıkaya'nın 1500 m. kadar kuzey-doğusunda bulunmaktadır. Kalede çıkan yangın nedeniyle yöre halkı tarafından Pişmiş Kale olarak adlandırılmaktadır. İlk kez 1800 yılında William Martin Leake tarafından, Küçük Asya'da bir tur adlı kitabında kalenin isminden bahsetmiş fakat lokasyonu hakkında bilgi vermemiştir (Leake, 1824: 24). 1834 yılında Mimar-Arkeolog C. Texier kaleye çıarak incelemelerde bulunmuştur (Texier, 2002: 357). 1861 yılında G. Perrot ve C. Chipiez tarafından Midas vadisinde yaptıkları araştırmalar kapsamında incelenmiştir (Perrot ve Chipiez, 1977: 155, fig: 113). 1893 y1lında M. Georges Radet tarafından gezilerek çizilmiş ve harita oluşturarak üzerine işaretlenmiş̧ir. Kalede 1939 y1lında Albert Gabriel yapılan bir deneme sondaj1 açılarak kullanım evreleri incelenmiştir (Gabriel, 1965: 80-82). C.H.E. Haspels tarafindan 19461958 yılları arasında Dağlık Phrygia Bölgesi'nde yapmış olduğu yüzey araştırmalarında kale detaylı olarak incelenerek mimari yapısı ortaya çıkartılmıştır (Haspels, 1971: 45, 128, fig. 60-76, 494, D, 507, 6, 508, 4). 1980 yılında G. de Francovich tarafindan incelenmiştir (Francovich, 1990: 101-102).

"Kral Yolu" üzerinde bir sınır karakolu olarak tanımlanan Pişmiş Kale'nin konumu nedeniyle önemli bir kale yerleşmesidir (Çambel, 1948: 586). Pişmiş Kale'den kuş uçumu 1350 m. 
kuzeydoğuda Akpara Kale, 470 m. güneyde Gökgöz Kale, 950 m. güneydoğuda, Kocabaş Kale, 1250 m. batıda Areyastis Anıtı yer almaktadır. Kaleye, kayaya oyulmuş merdivenlerle çıkılmaktadır. En tepede Midas Kale'de olduğu gibi iki kademeli bir akropol bulunur. Kalenin etrafi doğal kayaların oyulması ile elde edilen bir duvarla çevrilmiş, içinde kayaya oyulmuş odalar bulunmaktadır. Bunların bir bölümü erzak deposu, içleri sıvalı odalar ise su deposu ve tahıl ambarı olarak kullanılmıştır (Haspels, 1971: 44, fig. 60-76, 494, D, 507, 6, 508, 4; Berndt, 2002: 65). Kalenin güney bölümümde yapılan kazı çalışmaları sonucunda büyük bir kısmı yanmış tahıllar bulunmuştur. (Resim 8).

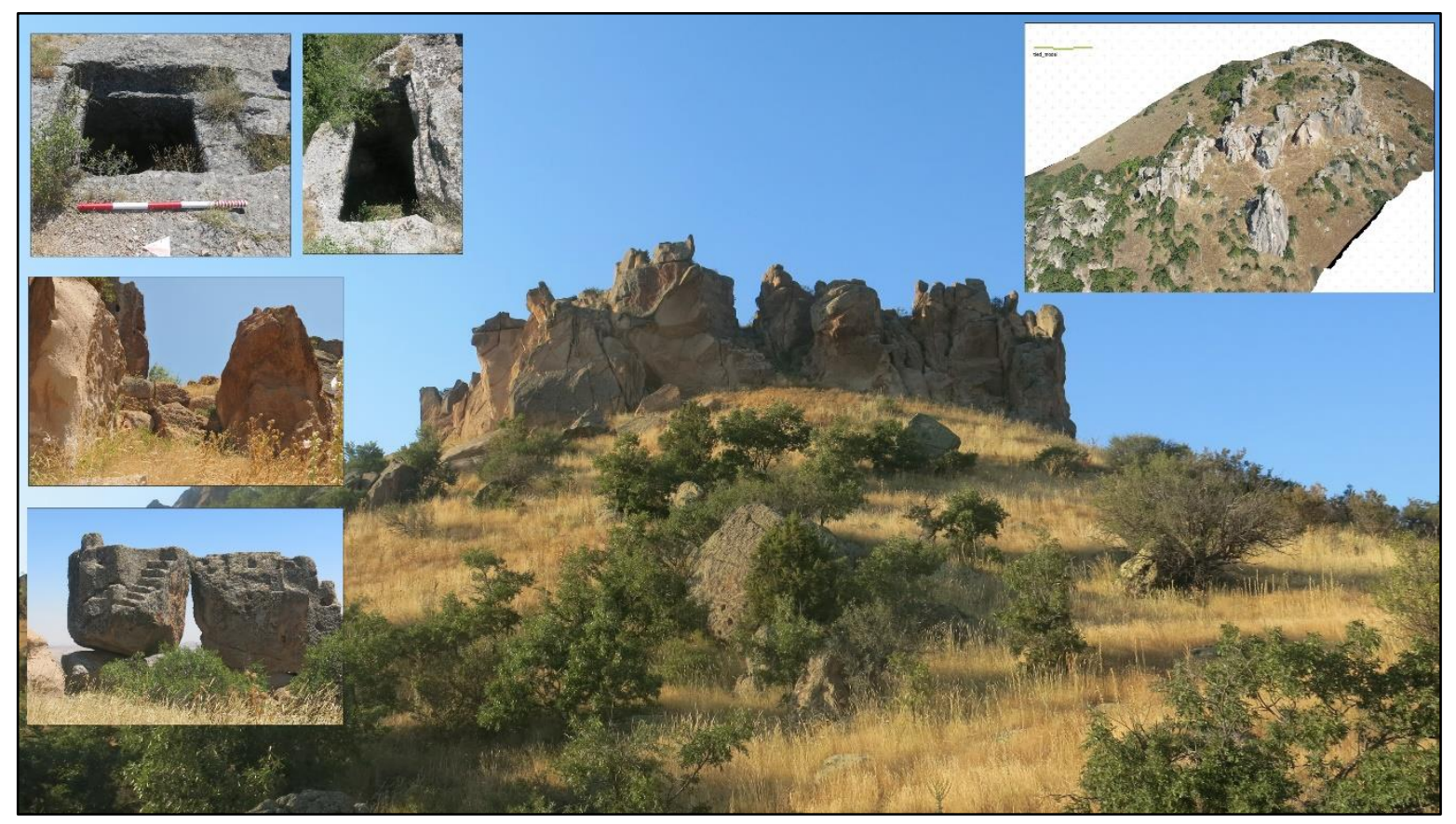

Resim 8: Pişmiş Kale

Kalenin üzerinde kenarları boyunca sıralanmış yoğun kayalıklar, bir kale duvarı gibi rol oynamaktadır. Kalenin şekli köşeli aynı zamanda düzensizdir. Bununla birlikte, kuzeydoğuda birinden diğer kenara geçiş bulunmaktadır. Kapının dışında, doğusunda yarım yuvarlak bir kayanın dışında küçük bir ileri karakola benzeyen bir geçit yer almaktadır. Kapının iç kısmında, platonun üst kısmına doğru kayadan yapılmış 6 basamak bulunmakta ve bu basamaklar günümüze oldukça aşınmış olarak ulaşmıştır.

Pişmiş Kale'nin ikinci Phryg kapısı iki kule ile yan taraftadır. Batı kule daha yüksektir. Bu kule doğal kayaya oyularak yapılmıştır. Kale platosundan küçük bir merdivenle kulenin platformuna çıkılır. Giriş batı kenardadır ve kapı geçidi ile sağlanır. Doğu Kule ise daha geniştir. 4 basamakla platodan ulaşılır. Kayada bir geçitle devam edilir. Güneye doğru ve kale kapısının dışında bir kaya nişi yer almakta ve yüksek kente girişi korumaktadır. Kuzey kenardaki platonun kenarı boyunca ise dikey kayalıklar sıralanmaktadır. Kapıdan batı köşeye doğru olasılıkla Phryg Dönemi'nde oluşturulan dıştan bakıldığında çok dik ve uzun bir savunma sistemi vardır. Düzenli, düz olan bu duvar, gerçek bir kale duvarı gibidir (Haspels, 1971: 43, fig. 60-76, 494, D, 507, 6, 508, 4). Bunların bir bölümü erzak deposu olarak kullanılmış olmalıdır. Yeni yüzey araştırmalarında Phryg, Roma ve Bizans Dönemlerine tarihlenen seramikler ile Pişmiş Kale'nin hemen güney eteğinde, anakayaya yapılmış bir Phryg mezarının güneyinde, kuzey-güney yönlü anakayaya açılmış antik yol tespit edilmiştir (Resim: 2). Yolun korunan kısmı 85,80 m uzunluğunda olup, Phryg mezarının önüne kadar izlenebilmektedir (Tamsü Polat, vd., 2019: 265). 


\section{Gökgöz Kale}

Eskişehir İli, Han İlçesi'ne bağlı Yazılıkaya Köyü'nün 2,5 km kuzeydoğusunda yer almaktadır. Deniz seviyesinden $1349 \mathrm{~m}$. yüksekliğindeki kalenin $850 \mathrm{~m}$. kuzeydoğusundan Gökgöz Deresi, 1200 m. kuzeybatısında Akpara Kale bulunmaktadır (Tamsü Polat, vd., 2019: 264). Yüksek bir tepe üzerine yerleştirilmiş dar bir gemi görünümündeki küçük kale düz bir alandadır. Kalenin savunma amaçlı yapıldığına dair fazla bir buluntu yoktur. Bu küçük kalenin, Pişmiş Kale'nin bir parçası olarak ileri karakol rolü oynamış olmalıdır. Midas Vadisi'ne bakan geniş batı duvarı tarafinda olan kale girişi çevresindeki kayalar oyularak, büyük bir dikdörtgen boşluk haline getirilmiştir (Haspels, 1971: 45, fig. 77). Kalenin batısında nişler, ahşap mimari konstrüksiyona ait ahşap yuvalar vardır (Tamsü Polat, vd., 2019: 264), (Resim 9).

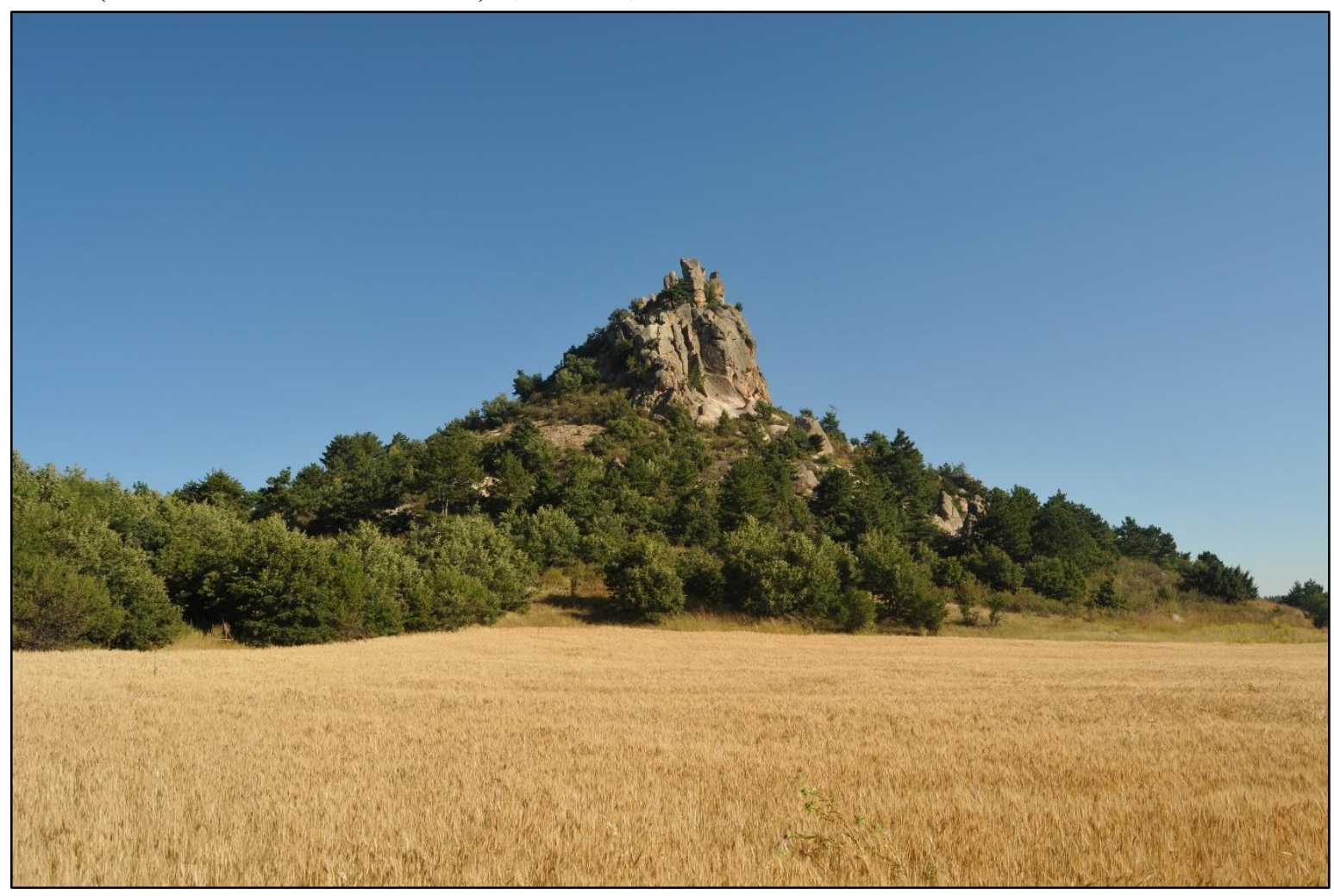

Resim 9: Gökgöz Kale

Haspels tarafindan 1946-1958 yılları arasında kale detaylı olarak incelenerek mimari yapısı ortaya çıkartılmıştır (Haspels, 1971: 40-45, fig. 77). 1980'de ise G. de Francovich tarafindan ziyaret edilmiştir (Francovich, 1990: 117). 2017 yılında yapılan yüzey araştırmalarında kalenin üst kısmında Bizans Dönemi'ne tarihlenen az miktarda seramik parçası bulunmuştur (Tamsü Polat, vd., 2019: 264).

\section{Akpara Kale}

Akpara Kale, günümüz Eskişehir İli, Seyitgazi İlçesi’ne bağlı, Çukurca Köyü’nün kuş uçumu 750 m. güneydoğusunda, Doğanlı Vadisi'nin doğusunda yer alır. Pişmiş Kale, Kocabaş Kale ve Gökgöz Kale'nin de kuzeybatısındaki son kaledir (Resim). Kalenin yaklaşık olarak $350 \mathrm{~m}$. doğusundan Akpara Deresi geçmektedir. Bu kalenin savunma amaçlı olarak kullanıldığına dair fazla bir bulgu olmamasına karşın, Yazılıkaya Vadisi'ne giriş ve çıkış noktasında olması nedeniyle önemli bir işlevi olduğunu düşündürmektedir (Polat ve Altan, 2012: 136), (Resim 10). 


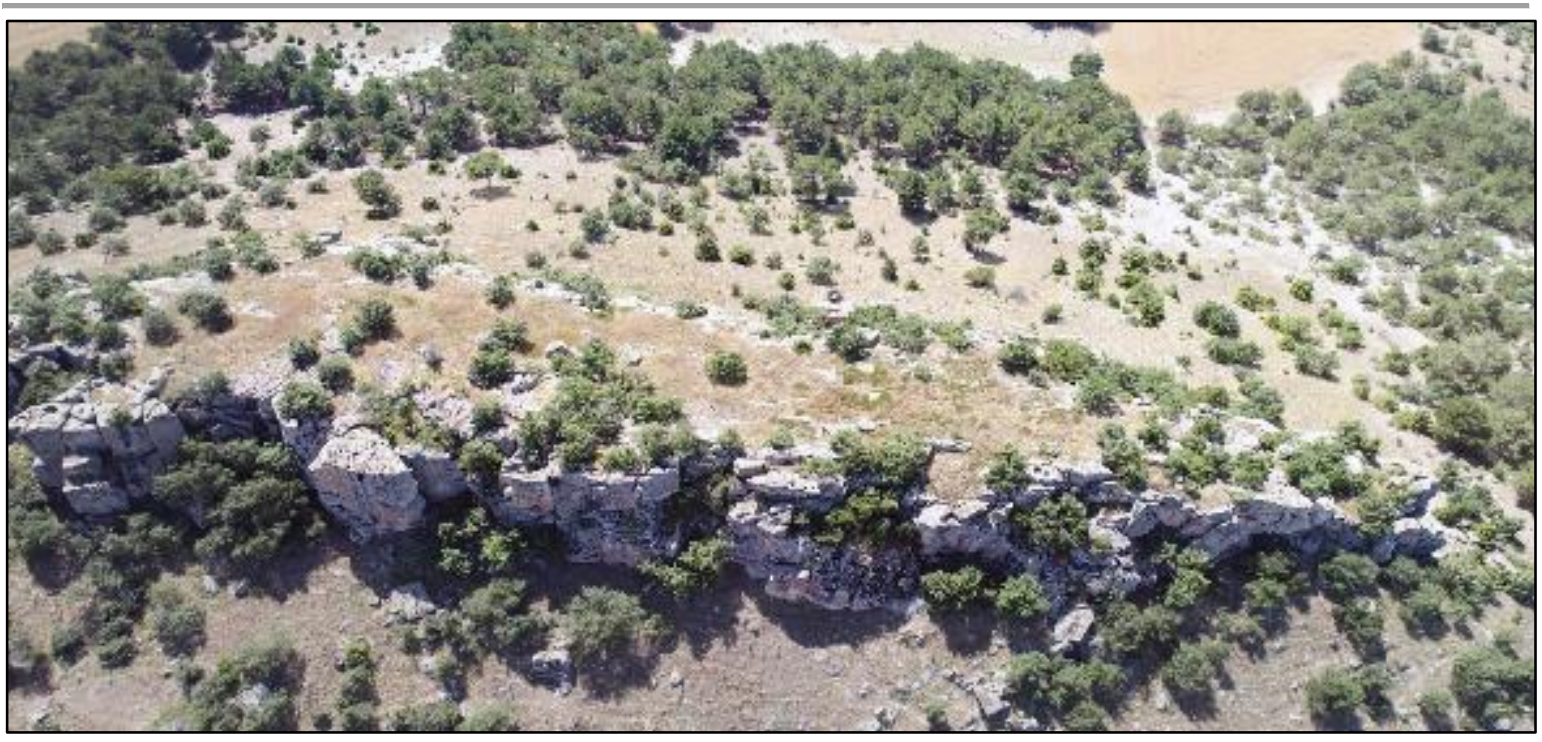

Resim 10: Akpara Kale

Batısında yüksek kayaların yer aldığı çam ve meşe ağaçları ile kaplı platolar yer alır (Haspels, 1971: 46). Kuzeyden güneye doğru devam eden dik kayalardan oluşur. Topografik olarak değerlendirildiğinde kale güneydoğuya doğru daralmaktadır.

Kalenin doğusunda, kuzey-güney yönünde düzgün kesilmiş taş bloklardan yapılmış anıtsal giriş kapısı vardır. Kapıya, günümüzde sekiz basamağı korunmuş, bir rampa ile ulaşılmaktadır (Resim 11). Üst platosunda ise olasılıkla bir ambar ya da geniş bir silo olarak kullanılmış olan, üst yapısı günümüze ulaşmamış bir oda, çeşitli büyüklüklerde sarnıç ve su biriktirme havuzları, depo alanları ve silolar bulunur (Haspels, 1971: 47). Kale kuzeyden güneye daha sonra güneydoğuya doğru devam eden dikey geniş kayalardan oluşmuştur. Uzun batı kenarda Çukurca Köyü’nden görünen kale, güneydoğuya doğru daralmaktadır. Bu alanda kaleye giriş kapısı yer almaktadır. Anıtsal kapı geniş ve düzgün kesilmiş taşlardan yapılmıştır. Kapıya giden kayalıkta sekiz basamak korunmuştur. Kapının yakınında platonun orta kesiminde kayadan dörtgen planda bir oda vardır ve bu oda tavan kısmı dışında korunmuştur. Bu oda bir ambar ya da geniş bir silo olmalıdır (Haspels, 1971: 46-48, fig. 59).

İlk olarak Haspels tarafindan araștırılan Akpara Kale (Haspels, 1971: 46-48, fig. 59), M. Belke tarafindan da incelenmiş (Belke ve Mersich, 1990: 258). G. de Francovich tarafindan da ziyaret edilmiştir (Francovich, 1990: 116-117).

Son yıllarda yapılan yüzey araştırmaları ile kalenin eteklerinde, iki yüzeyli aletler, kıyıcı ve satırlar bölgede Alt Paleolitik Dönem'in varlığının anlaşılmasını ve bu yeni tespitler ile vadinin çok erken dönemlerden itibaren yerleşim gördüğünü göstermesi açısından önemlidir (Erikan, 2019: 2334). Ayrıca yine kalenin kuzey ve batı yönünde eteklerde Kalkolitik Dönem'e (?) tarihlenen yoğun miktarda çakmaktaşı aletler tespit edilmiştir. Yine bu araştırmalarda Phryg ve Hellenistik Dönem'e tarihlenen seramikler, Akpara Kale'nin hemen kuzeydoğusundaki tepenin eteklerinde, MS 3.-4. yy aralığına tarihlendirilen toplam 12 adet kaya mezarının bulunduğu bir nekropolis saptanmıştır (Tamsü Polat, 2018: 273-295). 


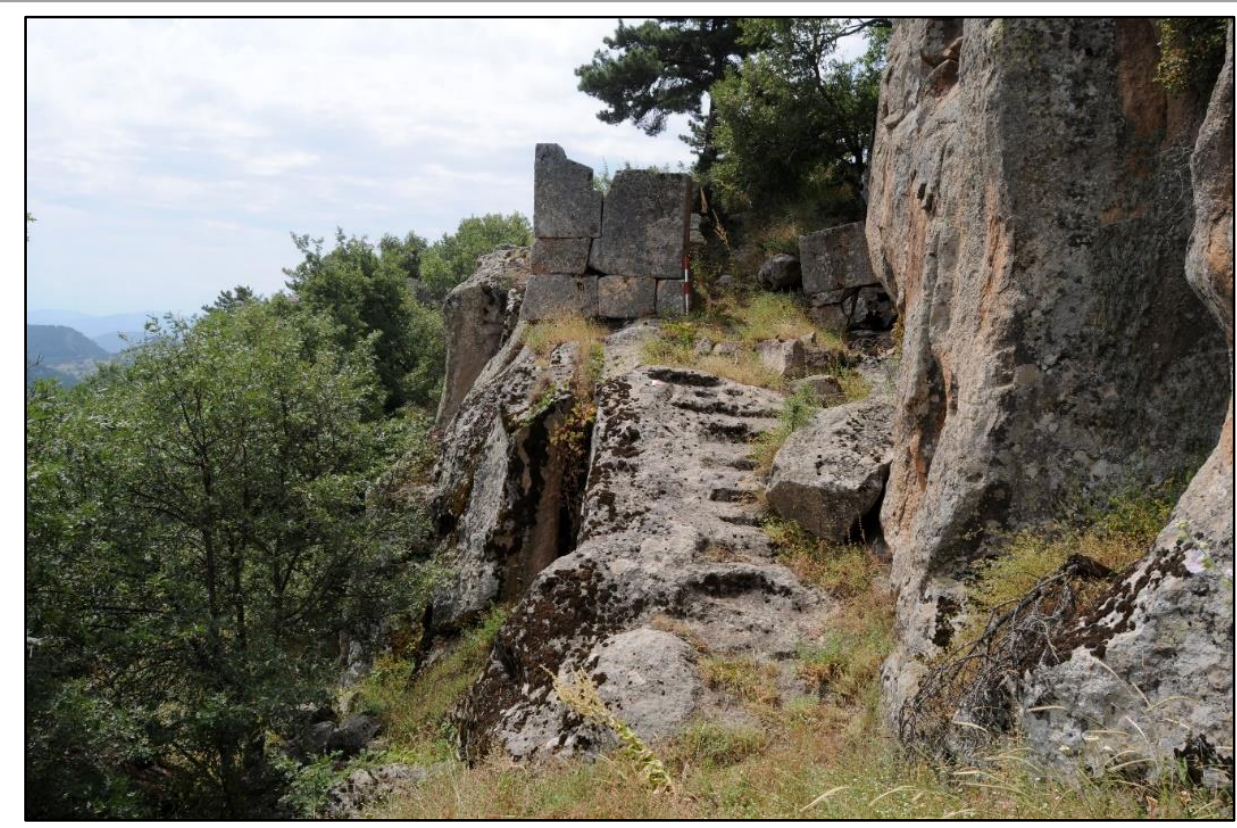

Resim 11: Akapara Kale Anitsal Giriş

\section{Değerlendirme ve Sonuç}

Phryg kaleleri Türkmen Dağı'nın güney ve güneydoğusundaki vadilerde yoğunlaşmıştır. Güneydoğuda yer alan Doğanlı, Yazılıkaya-Midas ve Kümbet Vadilerinde toplam 11 Phryg Kalesi bulunmaktadir.

Doğanlı Vadisi'ndeki, Doğanlı Kale ve Deve Boynu Kale olasılıkla Doğanlı Vadisi'ne hem de Midas Vadisi'ne giriş-çıkısı kontrol eden birer ön karakol niteliğinde olmalıdırlar. Doğanlı Vadisi'nin güneydoğusunda Yazılıkaya-Midas Vadisi'nin girişinde Akpara Kale bulunmaktadır. Bu kalenin güneydoğusunda sırasıyla, Pişmiş Kale, Kocabaş Kale, Gökgöz Kale, güneyinde ise Yazılıkaya-Midas Kale yer almaktadır. Akpara Kale'nin savunma amaçlı olarak kullanıldığına dair fazla bir bulgu olmamasına karşın Yazılıkaya Vadisi'ne girişi-çıkışı kontrol altında tuttuğundan önemli bir işlevi olduğu düşünülmektedir. Yazılıkaya-Midas Vadisi’nin batısı kayalık sıra tepelerle çevrilmiş doğal bir sur niteliğinde olmasına karşın, doğusu düzlüktür. Akpara Kale, Pişmiş Kale, Kocabaş Kale, Gökgöz Kale'nin bulunduğu alanlarda yükseltiler mevcuttur. Bu kalelerin aralarında geçiş olabilecek boşlukların olduğu görülmektedir. Özellikle Akpara Kale ile Gökgöz Kale, Pişmiş Kale ile Yazılıkaya-Midas Kale arasında bu durum gözlemlenmektedir. Buradaki doğal yükseltiler kullanılarak vadinin doğusunda savunma hattı oluşturulmuştur.

Yazılıkaya-Midas Vadisi'ndeki kalelerin yoğunluğunun diğer bir nedeni; bu vadide yer alan tüf kayalıklarına oyulmuş olan büyük ölçekli anıtların (fasad, altar ve nişler) varlığıdır. YazılıkayaMidas Vadisi, Phryg Uygarlığı'nın önemli bir yerleşim alanı, Yazılıkaya-Midas Şehri ise dinsel metropolüdür. Bu nedenle Phrygler savunma hattını güçlendirmek ve kutsal alanlarını güvence altına almak için, geçiş noktalarındaki kayalık tepeler üzerine doğal kayalıkları da kullanarak kaleler yapmışlardır. Yazılıkaya- Midas Vadileri'nde yer alan kalelerin birbirlerine olan uzaklıkları ortalama 1.5 km.'dir. Bu kaleler Yazılıkaya-Midas Vadisi'nde olduğu gibi, vadi boyunca bir hat üzerinde olmayıp, vadi geneline dağılmıştır. Vadinin geniş ve uzun olması, aynı zamanda Türkmen Dağı'nın uzantıları olan tepelerin bu vadinin güneyinde vadiye dik olarak gelmesi ile oluşan geçitlerin geniş olması nedeniyle, kaleler birbirlerine uzak konumlanmıştır. Kalelerin vadinin doğusunda, yani Yazılıkaya-Midas Vadisi'nin batısında yoğundur. Kümbet Vadisi'ndeki kaleler Yazılıkaya-Midas 
Kale ile bağlantılı olmalıdır. Çünkü Yazılıkaya-Midas Vadisi’ne güneybatıdan giriş Kümbet Vadisi'nin doğusundandır.

Kaleler, konumları nedeniyle ulaşılması güç yüksek noktalarda, vadilerin giriş-çıkışlarını kontrol edebilecek yerlerde ve plato kenarlarında yer almakta, çevresinde bulunan tarım ve ormanlık arazilerine yakınlıklarıyla dikkat çekmektedir. Stratejik konumları nedeniyle hemen hepsinin savunulması kolaydır. Yollara hâkim konumları nedeniyle yol güzergâhlarını kalelerden rahatlıkla kontrol edilebilmektedir.

Kalelerin çoğunluğu bağımsız yüksek tepeler üzerine konumlandırılmıştır. Kalelerin baktığı yönler incelenmiş, sonuçta tarım alanlarına ve su kaynaklarına yakın, çevreyi kontrol edebilecek noktalara konumlandırıldıkları belirlenmiştir. Özellikle Phryg anıtlarının bulunduğu YazılıkayaMidas Vadisi ve güneydoğusundaki Kümbet Vadisi'nde konumlanmış olan kaleler, bu vadilerin Phrygler'in en önemli kutsal alanları olduğuna işaret etmektedir. Bu nedenle de bu vadilerdeki topoğrafik yapıdan faydalanılarak savunma amaçlı kale yerleşmelerine ağırlık verilmiştir (Hazırlanan çalışma, 1703E058 no'lu proje ile Anadolu Üniversitesi, Bilimsel Araştırma Projeleri tarafindan maddi olarak desteklenmektedir).

\section{Kaynakça}

Antik Kaynaklar

Plinius, (1947), Naturalis Historia, (Çev.: H. Rackham), (Loeb).

Strabon, (1987), Coğrafya Anadolu: Kitap: XII-XIII-XIV, (Çev.: Adnan Pekman).

Stephanus Byzantinos, (1840), Etnicorum que supersunt, (Ed. A. Meineke).

Herodotos, (1991), Herodot Tarihi, (Çev. M. Ökmen).

\section{Modern Kaynaklar}

Ayday, C. ve Göktan, R.M. (1990). "A Preliminary Engineering Geology Study Directed To The Conservation Of Midas Monument", International Earth Sciences Congress On Aegean Regions, 1, (Edit. M.Y. Savaşcin ve A. H. Eronat), 102-108.

Ayday, C. ve Göktan, R.M. (1993). "Yazılıkaya (Midas) Anıtı Civarında Gözlenen Kaya Blok Devrilme ve Kayma Mekanizmaları", Türkiye Jeoloji Kurultayı Bülteni, 8, (Edit. Tuncay Ercan ve Sefer Örçen, 155-159.

Barth, H. (1860). Reise von Trapezunt Durch die Nördliche Hälfte Klein-Asiens nach Scutari im Herbst 1858. Gotha: Justus Perthes.

Belke, K.-Mersich, N. (1990), TIB 7. Phrygien und Pisidien, Viyana, Verlag der Österreichischen Akademie der Wissenschaften.

Berndt, D. (2002), Midasstadt in Phrygien. Eine sagenumwobene Stätte im Anatolischen Hochland, Mainz Am Rhein, Verlag Philipp von Zabern.

Chaput, E. (1941), Phrygie. Exploration Archéologique I. Géologie et Géographie Physique, Paris, İstanbul Fransız Anadolu Araştırmaları Enstitüsü.

Çambel, H. (1948), "Pişmiş Kale Kazısı”, Türk Tarih Kongresi, Sayı: III, TTK Basımevi, 586-587.

Çambel, H. (1952), "Frikya'da, Midas Şehri Yanında Bulunan Prehistorik Mezar”, Türk Tarih Kongresi, Sayı: IV, TTK Basımevi, 228-229.

De Laborde, L. (1938), Voyage de L'Asie Mineure par Messeurs Alexandre de Laborde, Becker, Hall, et Léon de Laborde. 
Erikan, F. (2019), "Yeni Buluntularla Yazılıkaya/Midas Vadisinde Yontmataş Buluntulara Dair İlk Gözlemler", Arkeoloji Dergisi, XXIV, Ege Üniversitesi, Edebiyat Fakültesi Yayınları, 2334.

Frankovich, G. (1990), Santuari e Tombe Rubestri dell'antica Frigia e un'indagine Sulle Tombe Della Licia, L'erma di Bretschneider.

Gabriel, A. (1948), "Frikya'da Midas Şehri Kazıları”, IV. TTK, 225-227.

Gabriel, A. (1952), "Frikya'da Midas Şehri Kazıları”, Türk Tarih Kongresi, Sayı: IV, TTK Basımevi, 225-228.

Gabriel, A. (1965), Phrygie Exploration Archeologique.

Haspels, C.H.E. (1948), "Phrygia'da Midas'in Kentinde Yapılan Kazılar”, Belleten, Sayı: III, TTK Basimevi, 535-537.

Haspels, C.H.E. (1971), The Highlands of Phrygia. Sites and Monuments. Princeton.

Haspels, C.H.E. (1981), “Midas Şehri Kazısı”, Belleten, XLV/II, Sayı:178, TTK Basımevi, 1-5.

Henrickson, R.C. (1994), "Continutiy and Discontinuity in The Ceramic Tradition of Gordion During The Iron Age", Anatolian Iron Ages 3. A. Çilingiroğlu-D. French, (Ed.), The British Institute of Archaeology at Ankara, 95-131.

Kealhofer, L.-Grave, P.-Voigt, M.M. (2019), "Dating Gordion: The Timing and Tempo of Late Bronze and Early Iron Age Political Transformation", Radiocarbon, Vol 61, Nr 2, 2019, 495 514. https://doi.org/10.1017/rdc.2018.152

Kortanoğlu, R.E. (2008), Hellenistik ve Roma Dönemlerinde Dağlık Phrygia Bölgesi Kaya Mezarları, Anadolu Üniversitesi Yayınları.

Körte, G. - A. Körte, (1904), Gordion: Ergebnisse der Ausgrabung im Jahre 1900. JDAI Erganzungsheft V,.

Leake, W.M. (1824), Journal of a Tour in Asia Minor. https://doi.org/10.1017/CBO9780511751097

Mordtmann, A.D. (1925), Anatolien Skizzen und Reisebriefe aus Kleinasien (1850-1859), Hannover.

Naumann, F. (1983), Die Ikonographie der Kybele in der phrygischen und der griechischen Kunst. Istanbuler Mitteilungen, supp. 28. Tübingen.

Özçatal, M.F. (1992), "Yazılıkaya, Uluçayır ve Karasakaltekke Kazı, Onarım ve Çevre Düzenleme Çalışmaları", II. MKKS, 209-232.

Özçatal, M.F. (1993), “Gerdekkaya ve Yazılıkaya'da 1991 Yılı Çalışmaları”, III. Müze Kurtarma Kazıları Semineri, Ankara Üniversitesi Basımevi, 419-439.

Perrot, G.-Chipiez, C. (1977), History of Art in Phrygia, Lydia, Caria and Lycia, Longwood Pres,.

Polat, Y. (2009), "Dağlik Phrygia Bölgesi Yerleşim Tiplerinin Coğrafi Bilgi Sistemleri (CBS) ile İncelenmesi”, Kültür Varlıklarının Belgelenmesi, (Ed. Çabuk, A. ve Alanyalı, F.), Anadolu Üniversitesi Yayınları, 104-118.

Polat, Y.-Altan, M. (2012), “Yazılıkaya-Midas Vadisi’nde Bulunan Kalelerin Konumsal İlişkilerinin 2 ve 3 Boyutlu Modellenmesi”, Anadolu Üniversitesi Sosyal Bilimler Dergisi, Eskişehir, 12/1, 131-142.

Prayon, F. (1987), Phrygische Plastik. Tübingen. 
Radet, M.G. (1895), "En Phrygie Rapport Sur Une Mission Scientifique en Asie Mineure", Nouvelles Arrchives, VI, Paris, 425-594.

Ramsay, W.M. (1882), “The Rock Necropolies of Phrygia”, JHS, III, London, 168. https://doi.org/10.2307/623525

Ramsay, W.M. (1888), "A Study of Phrygian Art I", JHS, IX: 350-382, London. https://doi.org/10.2307/623681

Roller, L.E. (1999), Ana Tanrıça'nın İzinde, (Çev. B. Avunç), Homer Kitabevi.

Roller, L.E. (2012), "Frig Dini ve Kült Uygulamalar1/Phrygian Religion and Cult Practise", Frigler, Midas'ın Ülkesinde, Anıtların Gölgesinde, (Ed. Taciser Tüfekçi Sivas ve Hakan Sivas) Yapı Kredi Yayınlar1, 202-233.

Steuart, J.R. (1842), A Description of Some Ancient Monuments With Inscriptions Still Existing in Lydia and Phrygia Several of Which are Supposed to be Tombs of the Early Kings, London.

Talbert A.-Richard, J. (2000), Barrington Atlas of The Grek and Roman World Map by Map Directory, Volume: II, Princeton University Pres.

Tamsü Polat, R. (2010), "Yeni Buluntular Işı̆̆ında Phryg Kaya Altarları ve Bir Tipoloji Önerisi”, Anadolu Üniversitesi Sosyal Bilimler Dergisi, 10/1, 203-222.

Tamsü Polat, R. (2018), "Yazılıkaya/Midas Vadisi Akpara Kaya Mezarları", OLBA XXVI, 261-284.

Tamsü Polat, R.-Polat, Y. (2018), "Eskişehir İli Yazılıkaya/Midas Vadisi Araştırmaları", Türk Eskiçağ Bilimleri Enstitüsü Haberler, say1: 44, 46-55.

Tamsü Polat, R.-Polat, Y.-Sancaktar, H.-Yürük, M.B. (2019), "Eskişehir İli Yazıllkaya/Midas Vadisi Yüzey Araştırması 2017”, AST, 36/3, 261-278.

Texier, C. (1839), Description de 1'Asie Mineure, faite par ordre da gouvernement Français, De 1833 A1837, I.

Tüfekçi Sivas, T. (1999), Eskişehir-Afyonkarahisar-Kütahya İl Sınırları İçindeki Kaya Anıtları, Anadolu Üniversitesi Yayınları.

Tüfekçi-Sivas, T. (2003), "Eskişehir, Kütahya, Afyonkarahisar İlleri 2001 Yılı Yüzey Araştırması”, 20. AST II, 285-298.

Tüfekçi-Sivas T. -Sivas, H. (2003), "Eskişehir, Kütahya, Afyonkarahisar İlleri Yüzey Araştırması, Arkeolojik Envanter Raporu", TÜBA-TÜKSEK 1, Ankara, Türkiye Bilimler Akademisi, 232. https://doi.org/10.22520/tubaked.2003.0001

Tüfekçi Sivas, T. (2012), "Frig Vadileri ve Kutsal Yazılıkaya-Midas Kenti/Phrygians Valleys and Sacret Yazılıkaya-Midas City", Frigler, Midas'ın Ülkesinde, Anıtların Gölgesinde, (Ed. Taciser Tüfekçi Sivas ve Hakan Sivas) Yapı Kredi Yayınları, 112-161.

Voigt, M.M. (2012), "The Unfinished Project of the Gordion Early Phrygian Destruction Level”, The Archaeology of Phrygian Gordion, Royal City of Midas. C. Brian Rose (Ed.), Philadelphia, University of Pennsylvania Museum of Archaeology and Anthropology, 67300. https://doi.org/10.9783/9781934536599.67

von Diest, W. (1898), Von Tilsit nach Angora. Forschungsreise zweier preufsischen Stabsoffiziere im Frühjahr1896. Gotha: Justus Perthses.

von Reber, F. (1897), "Die phrygischen Felsendenkmäler: Untersuchungen über Stil und Entstehungszeit”, Abhandlungen der Akademie der Wissenschaften, XXI/III, 531-598. 